\title{
Improvement of Solubility and Antifungal Activity of a New Aminothiophene Derivative by Complexation with 2-Hydroxypropyl- $\beta$-cyclodextrin
}

\author{
Giovanna R. A. Eleamen, ${ }^{a}$ Silvana C. da Costa, ${ }^{a}$ Reginaldo G. Lima-Neto, ${ }^{b}$ Rejane \\ P. Neves, ${ }^{b}$ Larissa A. Rolim, ${ }^{b}$ Pedro J. Rolim-Neto, ${ }^{b}$ Ricardo O. Moura, ${ }^{a}$ Thiago M. \\ de Aquino, ${ }^{c}$ Edson S. Bento, ${ }^{c}$ Marcus T. Scotti, ${ }^{d}$ Francisco J. B. Mendonça-Junior, ${ }^{a}$ \\ Elisangela A. M. Mendonça ${ }^{a}$ and Elquio E. Oliveira ${ }^{*, a}$ \\ ${ }^{a}$ Laboratório de Síntese e Vetorização Molecular (LSVM), Universidade Estadual da Paraíba, \\ 58071-160 João Pessoa-PB, Brazil \\ ${ }^{b}$ Departamento de Ciências Farmacêuticas, Universidade Federal de Pernambuco, \\ 50670-901 Recife-PE, Brazil \\ ${ }^{c}$ Laboratório de Ressonância Magnética Nuclear, Instituto de Química e Biotecnologia, \\ Universidade Federal de Alagoas, 57072-900 Maceió-AL, Brazil \\ ${ }^{d}$ Departamento de Engenharia e Meio Ambiente, Universidade Federal da Paraíba, Campus IV, \\ 58297-000 Rio Tinto-PB, Brazil
}

\begin{abstract}
This study aimed to prepare a complex of 2-hydroxypropyl- $\beta$-cyclodextrin (HP- $\beta$-CD) and $6 \mathrm{CN} 10$, a poorly water soluble 2 -aminothiophene derivative with antifungal properties, by freeze-drying technique. The complex was characterized by thermal analysis, infrared/Raman spectroscopy, X-ray diffraction and scanning electron microscopy. In addition, we used the data of the phase solubility study, ${ }^{1} \mathrm{H}$, and 2D NMR spectroscopy and molecular modeling in order to investigate the interactions between $6 \mathrm{CN1} 10$ and HP- $\beta-\mathrm{CD}$. The apparent solubility of $6 \mathrm{CN} 10$ with HP- $\beta-\mathrm{CD}$ increased more than 29 fold. The phase solubility assay in water at $25^{\circ} \mathrm{C}$ showed an $A_{P}$-type curve, with an apparent stability constant $\mathrm{K}_{1: 1}$ and $\mathrm{K}_{1: 2}$ of 96 and $0.1989 \mathrm{M}^{-1}$, respectively. The results of IR, NMR and docking indicate that $6 \mathrm{CN} 10$ is able to form complexes with HP- $\beta-C D$ (1:1 and 1:2 stoichiometric ratios), generating the formation of inclusion and preferably, non-inclusion complexes. The antifungal activity against Cryptococcus neoformans demonstrated the superior performance of the complex $\left(46.66 \mu \mathrm{g} \mathrm{mL}^{-1}\right)$ when compared with the free drug (166.66-333.33 $\left.\mu \mathrm{g} \mathrm{mL}^{-1}\right)$. The present study provides useful information for the potential application of complexation with low soluble compounds and about the type of complex formation between $6 \mathrm{CN} 10$ and HP- $\beta-\mathrm{CD}$.
\end{abstract}

Keywords: antifungal activity, inclusion complex, molecular modeling, NMR, solubility improvement

\section{Introduction}

2-Aminothiophene derivatives are an important class of heterocycles found in several biologically active compounds. ${ }^{1}$ This class of heterocycles has attracted great interest from researchers due to their great versatility as precursors of molecules with pharmacological properties. ${ }^{2}$ $6 \mathrm{CN} 10$ is a 2 -aminothiophene derivative synthesized via two-step reaction, starting with the obtainment of 2-amino-4,5,6,7-tetrahydro-4H-benzo[ $b]$ thiophene-3-

*e-mail: elquioeleamen@yahoo.com.br carbonitrile through the Gewald reaction, followed by condensation with 4-nitro-benzaldehyde to produce the 2-[(4-nitrobenzylidene)amino]-4,5,6,7-tetrahydro-4Hbenzo[b]thiophene-3-carbonitrile, called $6 \mathrm{CN} 10$ (Table 1$){ }^{3}$ This lipophilic drug showed good antifungal activity, with fungicidal profile, especially against Cryptococcus and can be considered a good prototype for the development of a new antimycotic drug. ${ }^{3}$ However, the therapeutic potential of $6 \mathrm{CN} 10$ is limited due its very poor water solubility. ${ }^{4}$

Cyclodextrins (CD) have been extensively used as complexing agents to improve the solubility and stability of a variety of poorly soluble and unstable drugs. ${ }^{5-7}$ 
Table 1. Hydrogen chemical shift data (ppm) and longitudinal relaxation times $\mathrm{T}_{1}(\mathrm{~s})$ of $6 \mathrm{CN} 10$ in the free state and in the complexes 1:1 and 1:2 molar ratios

\begin{tabular}{|c|c|c|c|c|c|c|c|c|}
\hline \multirow{2}{*}{$\begin{array}{l}6 \mathrm{CN} 10 \\
\text { hydrogen }\end{array}$} & \multicolumn{2}{|c|}{ Free } & \multicolumn{3}{|c|}{$1: 2$ complex } & \multicolumn{3}{|c|}{ 1:1 complex } \\
\hline & $\delta / \mathrm{ppm}$ & $\mathrm{T}_{1} / \mathrm{s}$ & $\delta / \mathrm{ppm}$ & $\Delta \delta / \mathrm{ppm}$ & $\mathrm{T}_{1} / \mathrm{s}$ & $\delta / \mathrm{ppm}$ & $\Delta \delta / \mathrm{ppm}$ & $\mathrm{T}_{1} / \mathrm{s}$ \\
\hline $\mathrm{Ha}$ & 8.7750 & 2.25 & 8.8088 & 0.0338 & 1.68 & 8.7990 & 0.0240 & 1.71 \\
\hline $\mathrm{Hb}$ & 8.3728 & 2.31 & 8.3904 & 0.0176 & 2.58 & 8.3849 & 0.0121 & 2.31 \\
\hline $\mathrm{Hc}$ & 8.2044 & 1.67 & 8.2104 & 0.0216 & 1.72 & 8.2044 & 0.0156 & 1.54 \\
\hline $\mathrm{Hd}$ & 2.7459 & 0.65 & 2.7494 & 0.0137 & 0.89 & 2.7459 & 0.0102 & 0.42 \\
\hline $\mathrm{He}$ & 2.6082 & 0.45 & 2.6129 & 0.0172 & 0.62 & 2.6082 & 0.0125 & 0.42 \\
\hline $\mathrm{Hf}$ & 1.8043 & 0.37 & 1.8062 & 0.0070 & 0.48 & 1.8043 & 0.0051 & 0.32 \\
\hline
\end{tabular}

CD structure provides a hydrophilic outer surface and hydrophobic interior hollow. The inner part of CD molecules is apolar due to the presence of glycosidic oxygens and methanetriyl protons, while its external surface is polar due to the presence of hydroxyl groups, which allow complexation with hydrophobic compounds improving its solubility. ${ }^{8,9}$ Nowadays, more than 35 different drugs are marketed as solid or solution-based CD complex formulations, including alprostadil, meloxicam, nicotine, omeprazole, itraconazole, aripiprazole, and insulin. ${ }^{10,11}$

Natural CDs have limited water solubility, which in turn negatively influences water solubility of the formed complex. ${ }^{5,12}$ To overcome this problem several modified CDs were introduced. 2-Hydroxypropyl- $\beta$-cyclodextrin (HP- $\beta-C D)$, a hydroxyalkyl derivative, is an alternative to natural CDs, with improved water solubility properties. Furthermore, there are toxicological studies pointing out that HP- $\beta-C D$ is well tolerated in animal models and humans by either oral or intravenous administration. ${ }^{7,9,13}$

The present work was carried out with the aim to evaluate the formation of 6CN10:HP- $\beta-C D$ complex to improve the aqueous solubility and consequently the antifungal activity of $6 \mathrm{CN} 10$. The prepared complexes were characterized by ${ }^{1} \mathrm{H}$ and $2 \mathrm{D}$ nuclear magnetic resonance (NMR) spectroscopy, Fourier transform infrared spectroscopy (FTIR), Raman spectroscopy, thermogravimetric analysis (TGA), X-ray diffractometry (XRD) and scanning electron microscopy (SEM). In addition, molecular modeling and docking studies of the complexes were performed to predict the models of interactions between $6 \mathrm{CN} 10$ and HP- $\beta-C D$ in the complexes. Finally, the antifungal activity of 6CN10:HP- $\beta$-CD complex was also evaluated.

\section{Experimental}

\section{Materials}

The $6 \mathrm{CN} 10$ was synthesized in our laboratory according to previously described methods. ${ }^{3}$ The 2-hydroxypropil$\beta$-cyclodextrin (HP- $\beta$-CD) was purchased from SigmaAldrich (Brazil). Other reagents, solvents and chemicals were of analytical reagent grade and were used without further purification.

Phase solubility studies of $6 \mathrm{CN} 10$ in 2-hydroxypropil- $\beta$ cyclodextrin

Phase solubility studies were carried out according to the method described by Higuchi and Connors. ${ }^{14} \mathrm{An}$ excess amount of $6 \mathrm{CN} 10(3 \mathrm{mg})$ was added to a series of water solutions containing different amounts of HP- $\beta-C D$, ranging from zero to its solubility limit. The suspensions were shaken at $25 \pm 1{ }^{\circ} \mathrm{C}$ until solubility equilibrium was reached $(72 \mathrm{~h})$. Then the samples were filtered through hydrophilic membrane filters $(0.22 \mu \mathrm{m})$. The concentration of $6 \mathrm{CN} 10$ in the filtrate was determined at $280 \mathrm{~nm}$ by UV-Vis spectrophotometer (Genesys 10S, Thermo Scientific, USA). Solubility data were fitted using linear regression. Assuming the formation of a complex with 1:1 stoichiometric ratio, the apparent stability constant $\left(\mathrm{K}_{1: 1}\right)$ of $6 \mathrm{CN} 10$ was calculated from the linear relationship between the molar concentration of $6 \mathrm{CN} 10$ in the solution medium as a function of the HP- $\beta$-CD molar concentration according to equation $1,{ }^{14}$ where the $S_{0}$ is the solubility of the $6 \mathrm{CN} 10$ in the absence of HP- $\beta-\mathrm{CD}$. The stability constant $\left(\mathrm{K}_{1: 2}\right)$ of $6 \mathrm{CN} 10$ was calculated 
from the equation 2 where [S0] is the solubility of the $6 \mathrm{CN} 10$ in the absence of $\mathrm{HP}-\beta-\mathrm{CD}$, and $[\mathrm{St}]$ and $[\mathrm{Lt}]$ are the concentrations of $6 \mathrm{CN} 10$ and $\mathrm{HP}-\beta-\mathrm{CD}$ in solution, respectively:

$\mathrm{K}_{1: 1}=$ slope $/ \mathrm{S}_{0} \times(1-$ slope $)$

$\mathrm{K}_{1: 2}=\left([\mathrm{St}]-\left[\mathrm{S}_{0}\right]\right) /[\mathrm{Lt}]=\mathrm{K}_{1: 1}[\mathrm{SO}]+\mathrm{K}_{1: 1} \mathrm{~K}_{1: 2}\left[\mathrm{~S}_{0}\right][\mathrm{Lt}]$

The complexation efficiency (CE) of 6CN10 was determined from data of the phase solubility curve according to equation $3 .{ }^{15}$

$\mathrm{CE}=$ slope $/(1-$ slope $)$

The 6CN10:HP- $\beta$-CD ratio was calculated according to the equation $4 .{ }^{16}$

6CN10:HP- $\beta-\mathrm{CD}=1 /(1+1 / \mathrm{CE})$

Preparation of $6 \mathrm{CN} 10: \mathrm{HP}-\beta-\mathrm{CD}$ inclusion complex

6CN10:HP- $\beta$-CD inclusion complexes were prepared using freeze-drying technique according to Mendonça et al. ${ }^{17} 6 \mathrm{CN} 10$ and HP- $\beta$-CD were weighed accurately in 1:1 and 1:2 molar ratios and dissolved in distilled water under agitation for $72 \mathrm{~h}$ at $25 \pm 1{ }^{\circ} \mathrm{C}$. The solution was frozen in liquid nitrogen and then lyophilized for $24 \mathrm{~h}$.

The total recovery was calculated according to the following equation:

Total recovery $(\%)=$ Recovered powder / Initial $(6 \mathrm{CN} 10$

$+\mathrm{HP}-\beta-\mathrm{CD}) \times 100$

\section{Preparation of physical mixture}

Stoichiometric amounts of $6 \mathrm{CN} 10$ and the HP- $\beta-\mathrm{CD}$ were weighed and mixed until a simply solid physical mixture was obtained.

Nuclear magnetic resonance (NMR)

${ }^{1} \mathrm{H}$ spectra and $\mathrm{H}-\mathrm{H}$ spatial dipolar correlation 2D NMR analysis were recorded for $6 \mathrm{CN} 10, \mathrm{HP}-\beta-\mathrm{CD}$ and complexes in 1:1 and 1:2 molar ratios dissolved in DMSO- $d_{6}\left(0.02 \mathrm{~mol} \mathrm{~L}^{-1}\right)$ using a Bruker AVANCE 400 spectrometer. The spectra were acquired at $25 \pm 1{ }^{\circ} \mathrm{C}$ in $5 \mathrm{~mm}$ tubes. Two-dimensional rotating-frame Overhauser effect spectroscopy (ROESY) experiments were recorded using the standard pulse sequence found in the Bruker pulse program library, applying a set of mixing times of 500, 300 or $150 \mathrm{~ms}$ under spin lock condition. During the acquisition, 256 increments were collected with 32 repetitions and the measured data matrix were processed as a matrix of $2 \mathrm{k}(\mathrm{F} 2)$ by $1 \mathrm{k}(\mathrm{F} 1)$ data points. The proton spin-lattice relaxation time $T_{1}$ was measured using the saturation method in a spectrometer working at $400 \mathrm{MHz} .{ }^{1} \mathrm{H}$ chemical shifts were referenced to DMSO (2.50 ppm).

Molecular modeling and docking

The structures of HP- $\beta-\mathrm{CD}$ and $6 \mathrm{CN} 10$ were submitted to molecular docking using the Molegro Virtual Docker v. 6.0.1 (MVD).$^{18}$ Both compounds were prepared using default parameter settings in the same software. Moldock score [GRID] algorithm was used as the score function. ${ }^{18}$ The docking procedure was performed using a GRID of $13 \AA$ of radius and $0.20 \AA$ of resolution covering the whole structure of HP- $\beta-\mathrm{CD}$ at the site of each structure. For the evaluation of the ligand, the following poses were used: internal electrostatic interactions, internal hydrogen bonds and additional dihedral terms between atoms $\mathrm{sp}^{2}$. The search algorithm selected was MolDock SE using 50 runs, 1500 interactions, population size of 50, 300 steps and the neighbor distance factor of 1 . For pose generation, an energy threshold value of 100 with minimum and maximum tries of 10 and 30 , respectively, were selected. For each run 10 poses were returned. After docking, two post-docking steps were performed: (i) energy minimization in order to prevent any inaccuracies due to energy grid approximations; (ii) optimization of hydrogen bonds of both compound and cyclodextrin. ${ }^{18}$

\section{Thermal analysis}

The thermogravimetric analysis was performed with a Shimadzu, model TGA Q60. Approximately $3 \mathrm{mg}$ of the samples $(6 \mathrm{CN} 10, \mathrm{HP}-\beta-\mathrm{CD}$, physical mixture and 6CN10:HP- $\beta$-CD inclusion complex) were placed in alumina pan and heated from 25 to $600{ }^{\circ} \mathrm{C}$ at a rate of $10^{\circ} \mathrm{C} \mathrm{m^{-1 }}$ under a nitrogen flow of $50 \mathrm{~mL} \mathrm{~min}^{-1}$.

\section{X-Ray diffractometry (XRD)}

The X-ray powder diffraction patterns were obtained at room temperature with a diffractometer (model D8 Advance, Bruker) using Ni-filtered $\mathrm{Cu}-\mathrm{K}$ radiation, a voltage of $30 \mathrm{kV}$ and a current of $30 \mathrm{~mA}$. The scanning rate was employed for 2 degrees min $^{-1}$ over a diffraction angle of $2 \theta$ ranging from 5 to 80 degrees. 
Fourier transform infrared (FTIR) and Raman spectroscopy

The FTIR and Raman spectroscopy was carried with a spectrophotometer (Vertex 70 RAM II, Bruker). The FTIR spectra of the samples were obtained in the range between 4000 and $400 \mathrm{~cm}^{-1}$ using the $\mathrm{KBr}$ technique. FT-Raman spectra were recorded in the range between 3500 and $70 \mathrm{~cm}^{-1}$ at a spectral resolution of $4 \mathrm{~cm}^{-1}$.

\section{Scanning electron microscopy (SEM)}

The surface morphology of the samples was evaluated by a scanning electron microscope (XL 30 ESEM, Philips) set at $20 \mathrm{kV}$. Prior to the examination, the samples were sputter coated with gold-palladium under argon atmosphere.

\section{Antifungal activity evaluation}

Four isolated Cryptococcus neoformans obtained from cerebrospinal fluid (CSF) of immunocompromised patients from the Tertiary Public Hospital at Recife, Brazil, were assessed. Clinical samples were processed for mycological diagnosis using standard methods (direct examination and isolation in culture) at the Medical Mycology Laboratory, Federal University of Pernambuco, Recife, Brazil. Direct examination was performed without needing to add staining or clarification for blood samples and with India ink staining to CSF. Cultures were prepared using Sabouraud dextrose agar (SDA) (Difco) with chloramphenicol (50 $\left.\mathrm{mg} \mathrm{mL}^{-1}\right)$ and incubated at $35^{\circ} \mathrm{C}$ in an aerobic atmosphere for 15 days. Pure cultures were transferred onto the surface of SDA for taxonomic identification. ${ }^{19,20}$ All clinical isolates were stocked in URM Culture Collection.

Pure 6CN10 and 6CN10:HP- $\beta-C D$ complexes were evaluated for antifungal potential. The concentrations tested ranged from 2 to $2048 \mu \mathrm{g} \mathrm{mL}^{-1}$.

Reference microdilution trays, containing serial drug dilutions were prepared by following the CLSI M27-A3 guidelines. ${ }^{21} 6 \mathrm{CN} 10$ and $6 \mathrm{CN} 10: \mathrm{HP}-\beta-\mathrm{CD}$ were dissolved in dimethyl sulfoxide (DMSO), and then stored at $-80{ }^{\circ} \mathrm{C}$.

In order to obtain a yeast inoculum containing 1.0 to

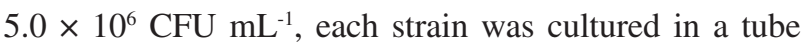
containing $20 \mathrm{~mL}$ of $4 \%$ Sabouraud dextrose agar (SDA; Difco) plus yeast extract at $35^{\circ} \mathrm{C}$ for two days. After that, yeast suspensions were prepared in sterile physiological solution $(0.85 \%)$ and adjusted to $90 \%$ transmittance at $530 \mathrm{~nm}$. Two serial dilutions from 1:100 and 1:20 were made to obtain

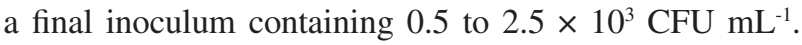

The tests were performed in RPMI 1640 medium buffered with 3-(N-morpholino)propanesulfonic acid (MOPS). Microplate wells were inoculated with $100 \mu \mathrm{L}$ of the previously obtained inoculum. The microplates were incubated at $35^{\circ} \mathrm{C}$ in a non- $\mathrm{CO}_{2}$ incubator and were visually evaluated $72 \mathrm{~h}$ after the incubation. The minimum inhibitory concentrations (MICs) corresponded to the lowest drug dilution that showed growth inhibition compared to the control wells. All tests were performed in duplicate.

\section{Results and Discussion}

\section{Phase solubility studies}

The phase solubility diagram is the most commonly used method to evaluate the effect of cyclodextrin in the aqueous solubility of a drug. ${ }^{14}$ The phase solubility profile of $6 \mathrm{CN} 10$ in aqueous solutions of HP- $\beta-\mathrm{CD}$ is presented in Figure 1 . The solubility of $6 \mathrm{CN} 10$ increased with a rise in the HP- $\beta$-CD concentration, showing a positive deviation from linearity, indicating an $\mathrm{A}_{\mathrm{P}}$-type phase solubility diagram. This may indicate the formation of $1: 1$ and $1: 2$ stoichiometric ratios of $6 \mathrm{CN} 10: \mathrm{HP}-\beta-\mathrm{CD}$ complexes. Furthermore, the $\mathrm{A}_{\mathrm{P}}$-type phase solubility diagram also indicated the formation of complex aggregates that can solubilize an additional amount of the guest molecules through non-inclusion complexation as also suggest by the study of molecular modeling and docking. ${ }^{22,23}$ The apparent solubility of $6 \mathrm{CN} 10$ with $0.36 \mathrm{~mol} \mathrm{~L} \mathrm{~L}^{-1}$ of HP- $\beta-\mathrm{CD}$ was increased by more than 29-fold, confirming the ability of the HP- $\beta$-CD to improve the apparent solubility of the $6 \mathrm{CN} 10$.

The $\mathrm{K}$ values are good indicators to estimate the binding strength between the ligand and host. ${ }^{14,23}$ The value of $\mathrm{K}_{1: 1}$ and $\mathrm{K}_{1: 2}$ were 94 and $0.1989 \mathrm{M}^{-1}$, respectively. A small $\mathrm{K}$ value indicates a weak interaction with a higher amount of free ligand, while large $\mathrm{K}$ value indicates the formation of a stable complex. The $\mathrm{K}_{1: 1}$ value was much larger than

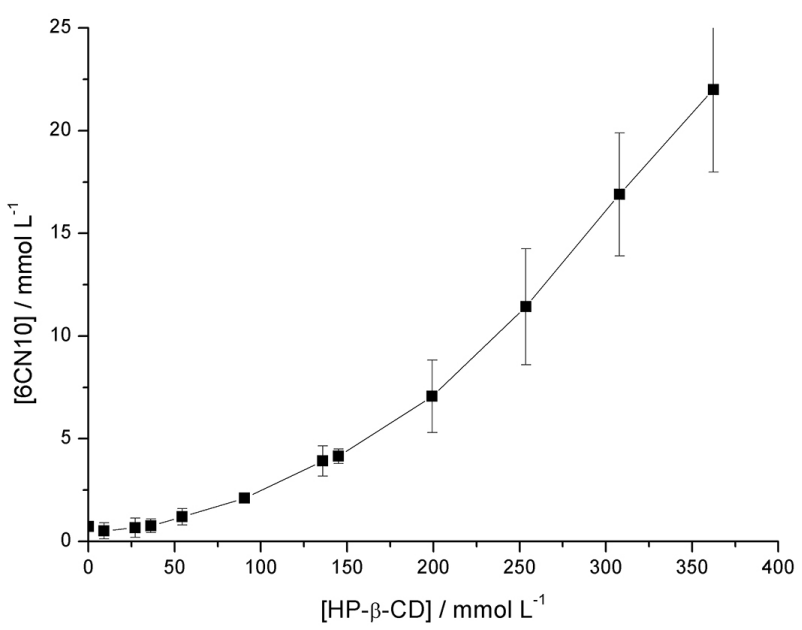

Figure 1. Phase solubility diagram of $6 \mathrm{CN} 10$ as a function of HP- $\beta-\mathrm{CD}$ concentrations in water at $25^{\circ} \mathrm{C}(\mathrm{n}=3)$. The linear fitting with regression analysis was $[6 \mathrm{CN} 10]$ water $=0.0565 \times[\mathrm{HP}-\beta-\mathrm{CD}]-1.6862\left(\mathrm{r}^{2}=0.9281\right)$. 
the $\mathrm{K}_{1: 2}$, indicating that the $1: 1$ complex is more stable than the 1:2 complex.

For poorly soluble drugs, like $6 \mathrm{CN} 10, \mathrm{~S}_{0}$ is in general much larger than the intrinsic solubility of the compound in water $\left(\mathrm{S}_{\text {int }}\right)$. This can lead to erroneous $\mathrm{K}$-values. According to Loftsson et al. ${ }^{16}$ a more accurate method for determination of the solubilizing efficiency of cyclodextrins with poorly soluble drugs is to determine their complexation efficiency due to the independence of both $S_{0}$ and $S_{\text {int }}$ in the calculation. The CE of $6 \mathrm{CN} 10$ in HP- $\beta-\mathrm{CD}$ solution, calculated according to equation 2 , was 0.059 . This value indicated that the molar ratio of [6CN10]:[HP- $\beta-\mathrm{CD}]$ was $1: 18$, which implies that the host will be responsible for a great increase in formulation bulk.

\section{Thermogravimetric analysis}

Thermal analyses can be used to detect the formation of inclusion complexes. When guest molecules are embedded in $\mathrm{CD}$ cavities, their melting, boiling or degradation points generally shift to a different temperature or disappear. ${ }^{6,24,25}$ Analyzing the $6 \mathrm{CN} 10$ and physical mixture, DTA curves with a peak at $186^{\circ} \mathrm{C}$ can be observed with an onset temperature $\left(\mathrm{T}_{\mathrm{ONSET}}\right) 183{ }^{\circ} \mathrm{C}$, corresponding to the melting point of the drug. However, in the complex this $\mathrm{T}_{\text {ONSET }}$ changes to $181^{\circ} \mathrm{C}$. A reduction in $\mathrm{T}_{\mathrm{ONSET}}$ in the melting point normally indicates a possible destabilization of the crystal lattice of the compound. This phenomenon indicates an improvement in the drug solubility due to the crystalline conformation being changed to an "arrangement" of lower energy. Furthermore, the degradation temperature of the complex, presented in Table 2, shows that the complexation confers stability to $6 \mathrm{CN} 10$, since with the complex formation the initial degradation temperature was displaced from 286 to $321{ }^{\circ} \mathrm{C}$. In the physical mixture a physical delay of the initial degradation temperature is also shown, although less effective when compared to the inclusion complex.

Table 2. Initial temperatures of melting and degradation of $6 \mathrm{CN} 10$, physical mixture and complex

\begin{tabular}{lcc}
\hline Sample & $\begin{array}{c}\mathrm{T}_{\text {ONSET }} \text { melting } \\
\text { point } /{ }^{\circ} \mathrm{C}\end{array}$ & $\begin{array}{c}\mathrm{T}_{\text {ONSET }} \\
\text { degradation } /{ }^{\circ} \mathrm{C}\end{array}$ \\
\hline 6CN10 free & 183.12 & 286.89 \\
6CN10:HP- $\beta-C D$ physical mixture & 183.00 & 314.81 \\
6CN10:HP- $\beta$-CD complex & 181.33 & 321.16 \\
\hline
\end{tabular}

\section{X-Ray diffraction}

Powder X-ray diffractometry is a useful method for the detection of $\mathrm{CD}$ complexation in powder or microcrystalline states. The XRD patterns of $6 \mathrm{CN} 10, \mathrm{HP}-\beta-\mathrm{CD}$, physical mixture and the corresponding inclusion complex are presented in Supplementary Information (Figure S1). The XRD pattern of pure drug presented several diffraction peaks that demonstrate the crystalline nature of the drug. The HP- $\beta$-CD exhibited a typical crystalline diffraction pattern, confirming its amorphous character. The XRD pattern of $6 \mathrm{CN} 10$ and HP- $\beta$-CD physical mixture presented the characteristic of the HP- $\beta-C D$, whereas some crystallinity peaks of the drug were observed. The sharp peaks of the pattern indicated the retention of the crystalline structure of $6 \mathrm{CN} 10$ in the physical mixture. However, the XRD pattern of the inclusion complex was evidently different from the XRD patterns of the raw materials, with an intense reduction in the sharp peaks, indicating the formation of amorphous material. These results indicate the formation of $6 \mathrm{CN} 10: \mathrm{HP}-\beta-\mathrm{CD}$ complexes.

\section{Scanning electron microscopy}

The SEM photographs of $6 \mathrm{CN} 10, \mathrm{HP}-\beta-\mathrm{CD}, 6 \mathrm{CN} 10$ and HP- $\beta-C D$ physical mixture and 6 CN10:HP- $\beta-C D$ complex are presented in Figure 2. The $6 \mathrm{CN} 10$ is presented as a needle-like crystal, whereas HP- $\beta-C D$ was observed as an amorphous compound. In the $6 \mathrm{CN} 10$ and HP- $\beta-\mathrm{CD}$ physical mixture the characteristic of the HP- $\beta-C D$ and $6 \mathrm{CN} 10$ crystal is clearly observed. However, the SEM of the complex showed that the original morphology of the raw materials disappeared, and it was not possible to differentiate the $6 \mathrm{CN} 10$ and HP- $\beta-\mathrm{CD}$. These changes in the morphologic aspect of the complex samples suggest the existence of a single phase as previously related. ${ }^{26,27}$ The comparison of these images suggests the formation of the complex between the $6 \mathrm{CN} 10$ and the HP- $\beta-\mathrm{CD}$.

\section{Fourier transform infrared and Raman spectroscopy}

The FTIR spectra of $6 \mathrm{CN} 10, \mathrm{HP}-\beta-\mathrm{CD}, 6 \mathrm{CN} 10$ and HP- $\beta$-CD physical mixture and 6 CN10:HP- $\beta$-CD complex are presented in Figure 3. The FTIR spectrum of $6 \mathrm{CN} 10$ shows the presence of the main characteristic bands of $\mathrm{C}-\mathrm{H}$ stretch (aliphatics and aromatics) at 2850-3050 $\mathrm{cm}^{-1}$, the $\mathrm{C} \equiv \mathrm{N}$ stretching at $2221 \mathrm{~cm}^{-1}$ and the symmetric and asymmetric stretching vibration of nitro group $\left(\mathrm{NO}_{2}\right)$ at 1553 and $1346 \mathrm{~cm}^{-1}$. The most characteristic bands of $\mathrm{HP}-\beta-\mathrm{CD}$ appeared at $3402(\mathrm{O}-\mathrm{H}$, characterizing the presence of intermolecular hydrogen bonds); $2931(\mathrm{C}-\mathrm{H})$; 1159, 1083 and 1031 (C-H and C-O-C). These results are in agreement with the previous studies. ${ }^{17,28}$ The IR spectrum of the physical mixture did not differ significantly from those of the single components and can be interpreted as 

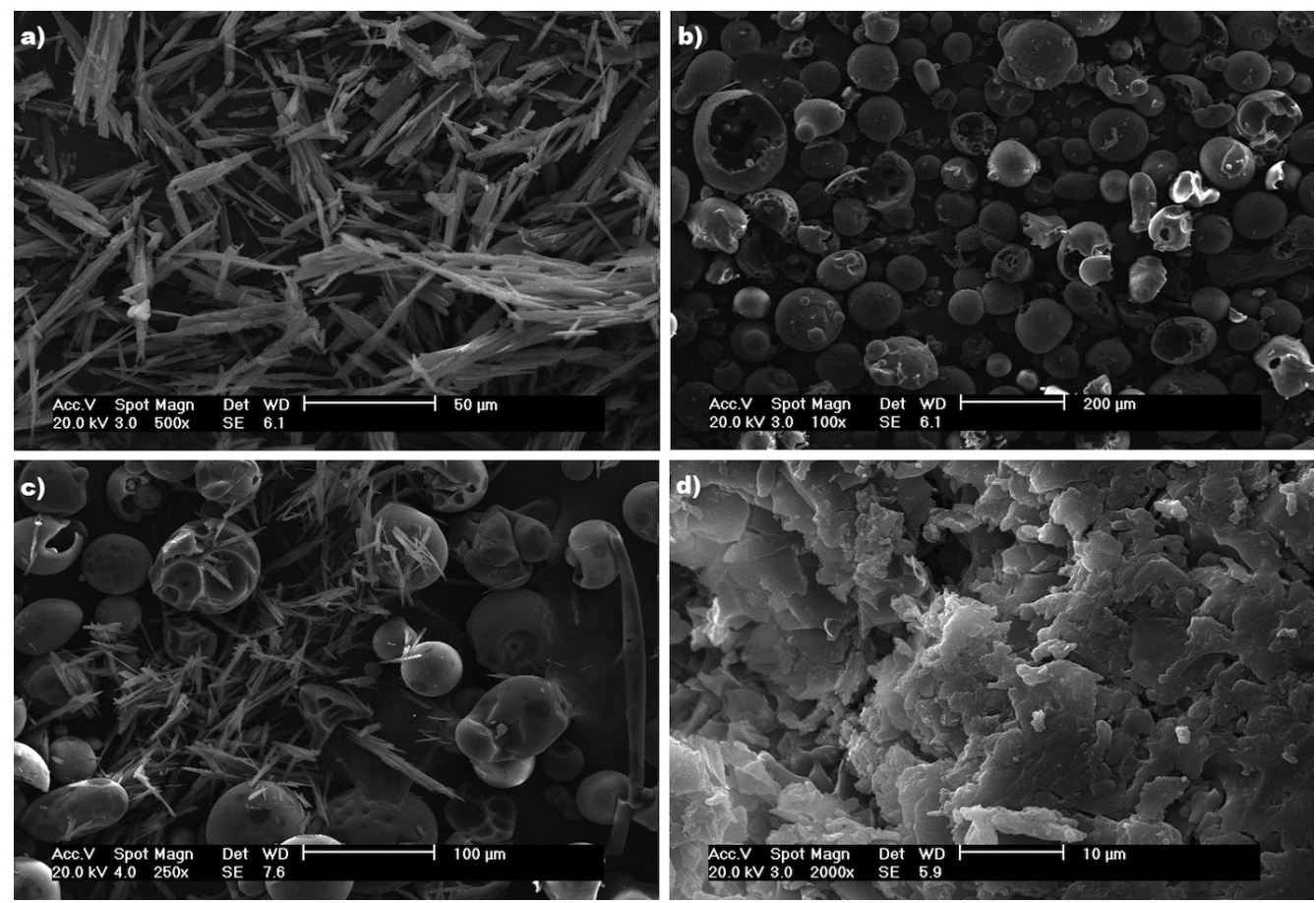

Figure 2. Scanning electron microscopy of (a) $6 \mathrm{CN} 10$; (b) HP- $\beta-\mathrm{CD}$; (c) physical mixture and (d) 6CN10:HP- $\beta-\mathrm{CD}$ complex.

the linear combination of the corresponding $6 \mathrm{CN} 10$ and HP- $\beta$-CD spectra. Analyzing the $6 \mathrm{CN} 10: \mathrm{HP}-\beta-\mathrm{CD}$ complex spectrum, a narrowing of the absorption band around $3402 \mathrm{~cm}^{-1}$ can be observed due to the axial deformation of $\mathrm{O}-\mathrm{H}$ stretch. Alteration in the intensity in this broad peak was previously associated with the formation of inclusion complex. ${ }^{28}$ Furthermore, a significant decrease in the intensity of all characteristic absorptions bands of $6 \mathrm{CN} 10$ was observed, probably owing to a restriction in the vibration related to the complexation process.

This phenomenon is observed in all spectra, however, it is better evidenced in the region of the symmetric and asymmetric stretching vibration of the nitro group (bands at 1553 and $1346 \mathrm{~cm}^{-1}$ ) and symmetric and asymmetric stretching of the imine group (band at $1590 \mathrm{~cm}^{-1}$ ).

These changes in FTIR spectra suggest that the interaction between the $6 \mathrm{CN} 10$ and HP- $\beta-\mathrm{CD}$ does not occur by an inclusion process, which is generally observed only decrease in the intensity of the absorptions bands of the functional groups that are within the cyclodextrin cavity, or very close to the cavity. ${ }^{28,29}$ Furthermore, no additional peaks were detected in the spectrum of $6 \mathrm{CN} 10: \mathrm{HP}-\beta-\mathrm{CD}$ complex, indicating the absence of any chemical reactions between $6 \mathrm{CN} 10$ and $\mathrm{HP}-\beta-\mathrm{CD}$.

Raman spectroscopy has been used as a complementary technique to evaluate the complex formation..$^{30-33}$ This technique presents a clear advantage when compared to the analogous FTIR spectra due to the relative silence of the cyclodextrin in the Raman spectra, which does a)

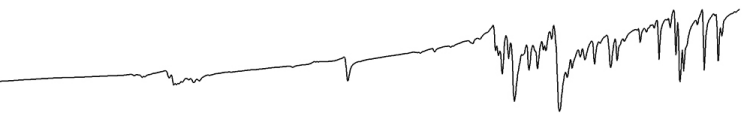

b)

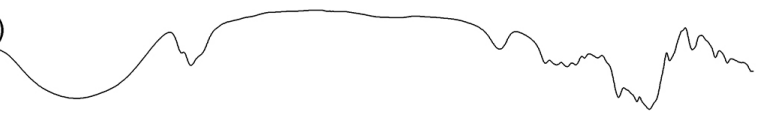

c)

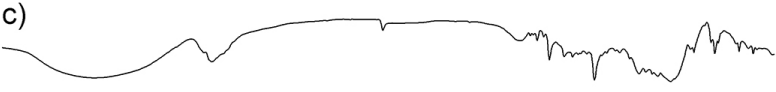

d)
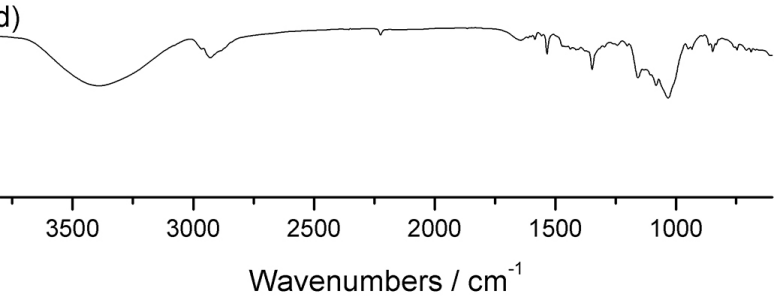

Figure 3. FTIR spectra of (a) 6CN10; (b) HP- $\beta$-CD; (c) physical mixture and (d) 6 CN10:HP- $\beta-C D$ complex.

not show any relevant overlap in the spectral patterns, permitting a better comparison between the free and the included molecule. ${ }^{34}$

Raman spectra showed a decrease in the peak intensity in the 6CN10:HP- $\beta$-CD complex when compared with the $6 \mathrm{CN} 10$ and with the $6 \mathrm{CN} 10$ and HP- $\beta-\mathrm{CD}$ physical mixture spectra (Figure 4). Such attenuation of signal intensity was previously connected to a reduction of electron molecular polarizability within the complex probably due the interactions between the compound and CD. ${ }^{32,33}$ Similar to the results obtained in the FTIR spectra, no spectral 
difference from the free $6 \mathrm{CN} 10$ and $6 \mathrm{CN} 10$ in the complex was observed, reinforcing the absence of any chemical reaction between $6 \mathrm{CN} 10$ and $\mathrm{HP}-\beta-\mathrm{CD}$.

\section{Nuclear magnetic resonance study}

$1 \mathrm{D}$ and $2 \mathrm{D}{ }^{1} \mathrm{H}$ NMR analysis were used for study complex formation in solution phase. The differences in hydrogen chemical shifts between 6CN10 in the free and in the complexed states were analyzed and are presented in Table 1. The influence of HP- $\beta-C D$ on the chemical shifts of 6CN10 hydrogens is also shown in Supplementary Information. An upfield shift displacement, as observed, indicates the existence of weaker interaction (van der Waals forces) between 6CN10 hydrogens and cyclodextrin chains. Moreover, $\mathrm{T}_{1}$ values of the $6 \mathrm{CN} 10$ hydrogens signals change between the free and the complexed states, indicating a change of $6 \mathrm{CN} 10$ dynamics, which suggest the existence of formation of both complexes (1:2 and 1:1 molar ratios) (Table 1). ${ }^{35,36}$
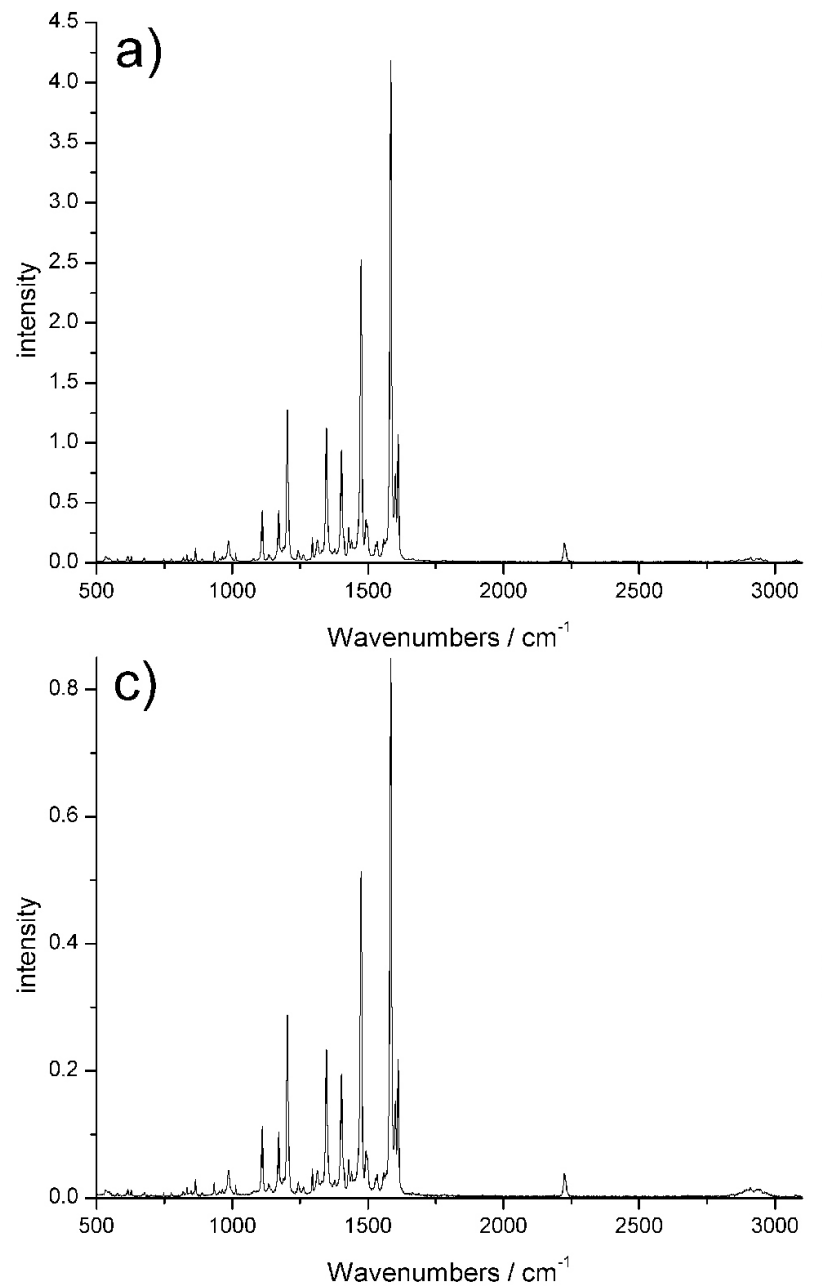

To obtain further information on the complex formation, 2D ROESY experiments were performed in order to evaluate the mode of complexation and spatial arrangement between 6CN10 and HP- $\beta-C D$ atoms. Intermolecular cross-peaks were observed between imine and aromatic hydrogens of $6 \mathrm{CN} 10$ and HP- $\beta-\mathrm{CD}$ hydrogens (Figure 5), corroborating the ${ }^{1} \mathrm{H}$ NMR data that showed that the major changes in the chemical shifts happened in the imine and aromatic hydrogens of 6CN10 in complex.

The 2D ROESY results also suggest that complexes $1: 2$ and 1:1 molar ratios were formed between $6 \mathrm{CN} 10$ and HP- $\beta-C D$, but as the individual HP- $\beta-C D$ hydrogens could not be assigned to resonance signals, inclusion process by noncovalent interactions cannot be confirmed using 2D NMR technique.

\section{Molecular modeling and docking study}

The molecular docking performed showed that $6 \mathrm{CN} 10$ has a greater length than the width of the cavity of
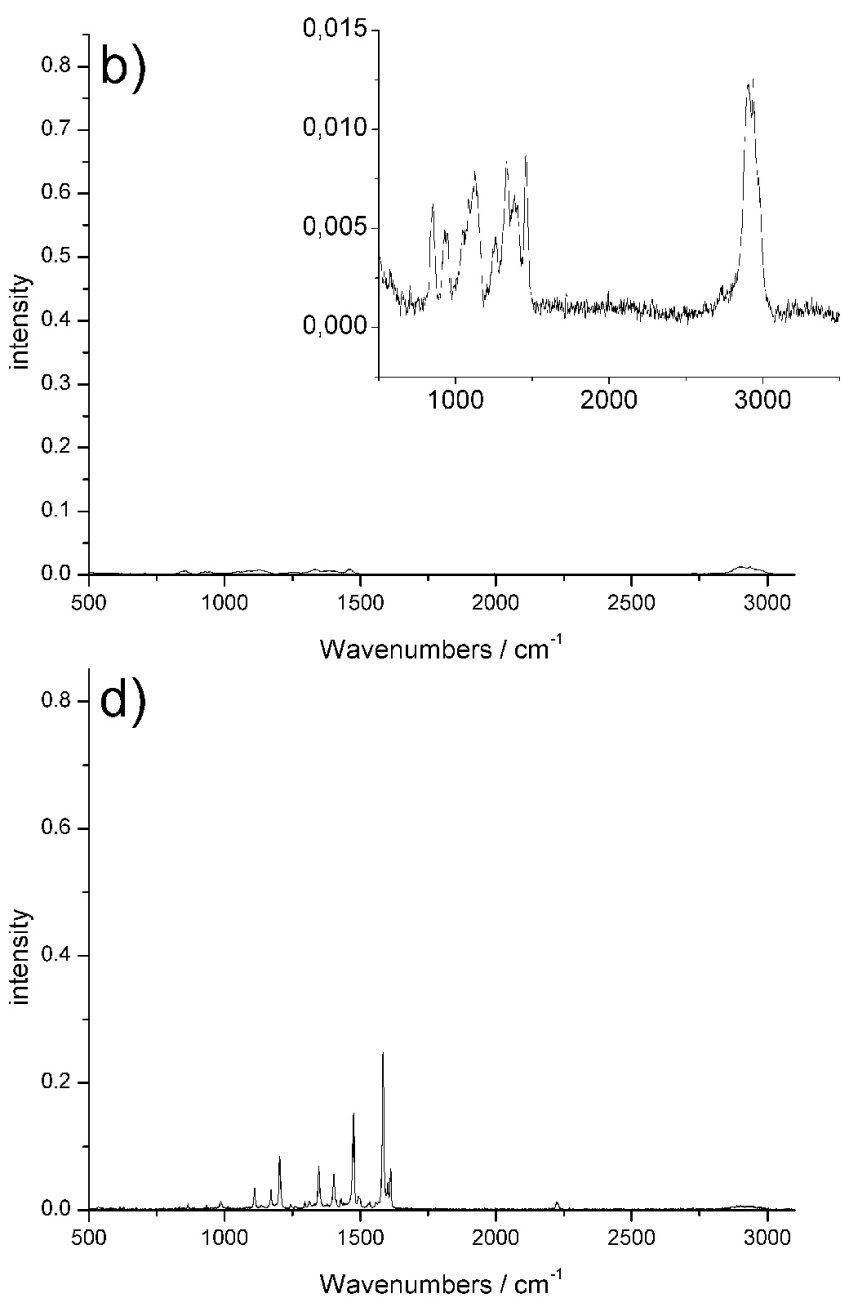

Figure 4. Raman spectra of (a) 6CN10; (b) HP- $\beta-\mathrm{CD}$; (c) physical mixture and (d) 6CN10:HP- $\beta-C D$ complex. 


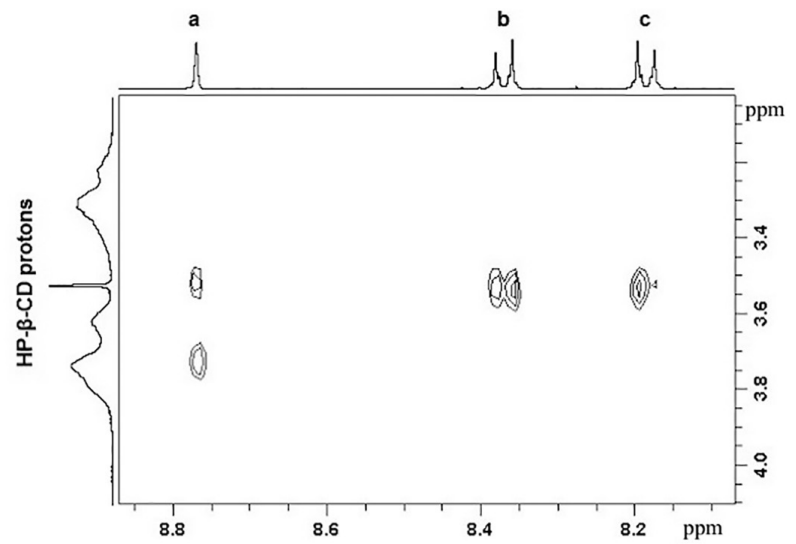

Figure 5. Expansion of a 2D ROESY of 6CN10:HP- $\beta-C D$ complex 1:1 molar ratio in DMSO- $d_{6}$.

1

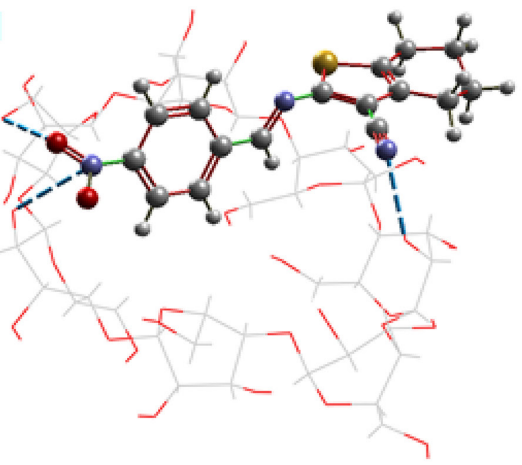

$E=-105.629$

3

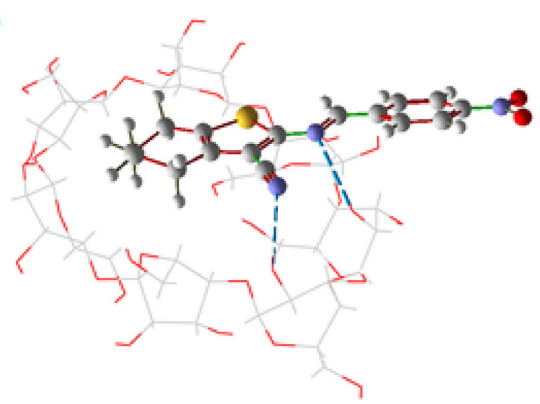

$E=-93.435$

5

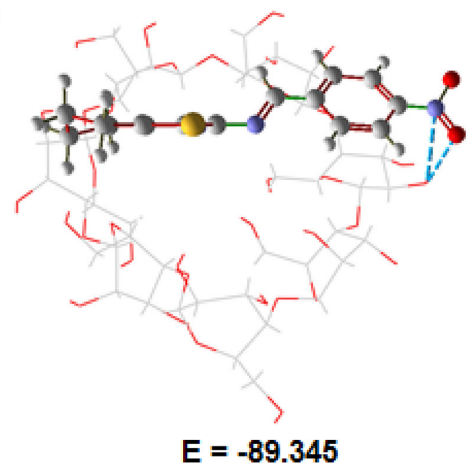

HP- $\beta$-CD. In Figure 6 we can observe the six 3D positions with lower energies along with the hydrogen bonds and their energy values $\left(\mathrm{E}_{\mathrm{dock}}\right)$. The dashed lines in each position represent hydrogen bonds between $6 \mathrm{CN} 10$ and HP- $\beta-\mathrm{CD}$. The groups responsible for these interactions in $6 \mathrm{CN} 10$ are the radicals 4-nitro $\left(-\mathrm{NO}_{2}\right)$, and the nitrogen of the nitrile $(-\mathrm{C} \equiv \mathrm{N})$ and imine $(-\mathrm{C}=\mathrm{N}-)$ and represent the strongest interactions between the HP- $\beta-\mathrm{CD}$ and $6 \mathrm{CN} 10$, which contribute to stabilization of the complex (data also observed in the ${ }^{1} \mathrm{H}$ NMR and ROESY).

Among the six lowest energy positions, in five different poses the $6 \mathrm{CN} 10$ is over the cyclodextrin cavity but not inside (poses 1-5). The only position in which the $6 \mathrm{CN} 10$ is inside the cavity (position $6, \mathrm{E}_{\text {dock }}=-91.136 \mathrm{~kJ} \mathrm{~mol}^{-1}$ )
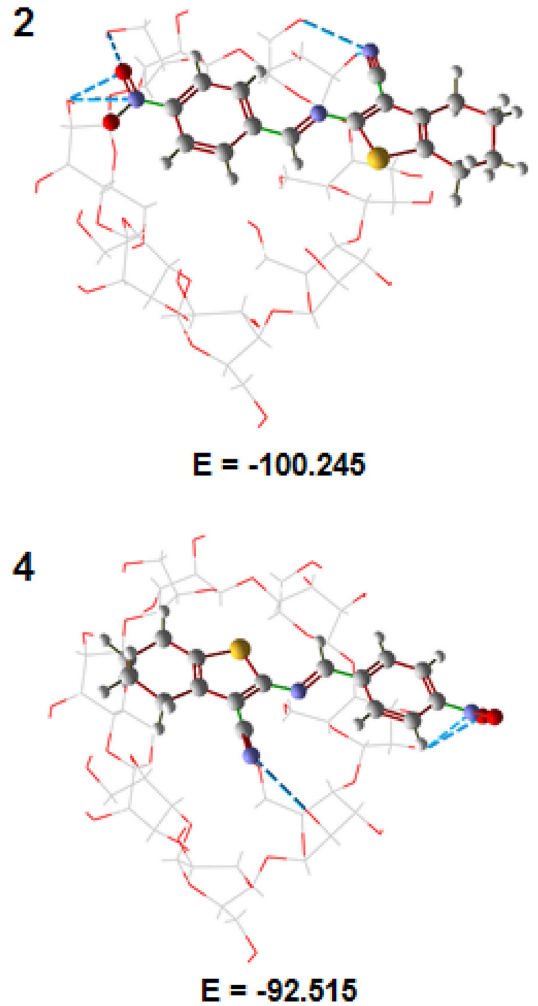

6

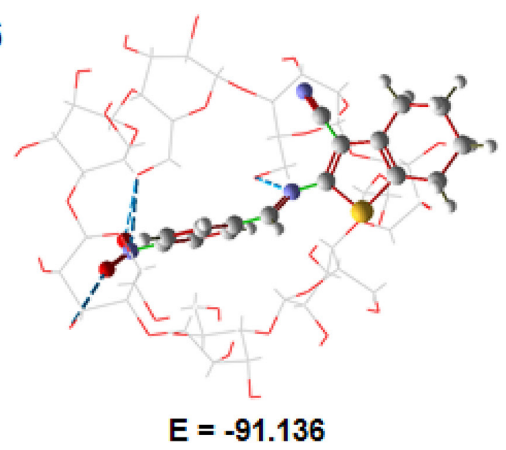

Figure 6. Six lower energy positions obtained through the docking study between $6 \mathrm{CN} 10$ and HP- $\beta$-CD. Dashed lines represent $\mathrm{H}$-bonds. $\mathrm{E}_{\mathrm{dock}}$ values are in $\mathrm{kj} \mathrm{mol}^{-1}$. 
Table 3. Antifungal activity of free 6CN10 and 6CN10:HP- $-\mathrm{CD}$ complex against Cryptoccocus neoformans

\begin{tabular}{lcccc}
\hline \multirow{2}{*}{ Formulation } & \multicolumn{4}{c}{ Tested strains $\left(\mathrm{MICs} /\left(\mu \mathrm{g} \mathrm{mL}^{-1}\right)\right)$} \\
\cline { 2 - 5 } & C. neoformans URM 6895 & C. neoformans URM 6901 & C. neoformans URM 6907 & C. neoformans URM 6909 \\
\hline 6CN10-complex & 46.66 & 46.66 & 46.66 & 46.66 \\
6CN10 pure & 333.33 & 333.33 & 166.66 & 166.66 \\
\hline
\end{tabular}

there is a higher energy value than four of the five positions (positions 1 to 4 ) found outside the cavity (Figure 6). The energy difference is very significant (higher than 10\%) when comparing positions 1 and 2 (outside the cavity) with position 6 (inside the cavity).

These docking results indicate that the $6 \mathrm{CN} 10$ is able to form stable complexes with HP- $\beta-C D$, but the interaction preferably takes place by the outer portion of HP- $\beta-C D$, generating non-inclusion complexes.

These results also support and are in accordance with the IR and NMR data. Since, if there was a preferential or exclusive formation of inclusion complexes between $6 \mathrm{CN} 10$ and HP- $\beta-\mathrm{CD}$, we would not expect to observe deviations in the chemical shifts and in the $T_{1}$ values of all 6CN10 hydrogens and a decrease in the intensity of all characteristic absorptions bands of $6 \mathrm{CN} 10$ as found in our study.

Based in these NMR and docking data, associated with the phase solubility results, we can affirm that the $6 \mathrm{CN} 10$ is able to form stable complexes with HP- $\beta-C D$, however, the differences observed in the curve lead us to believe in the concomitant existence of different populations of 6CN10:HP- $\beta-C D$ complexes, including inclusion and preferably, non-inclusion complexes.

\section{Antifungal activity evaluation}

Comparative data of the antifungal activity of free 6CN10 and 6CN10:HP- $\beta-\mathrm{CD}$ complex are presented in Table 3 . As can be seen, both the free $6 \mathrm{CN} 10$ and the $6 \mathrm{CN} 10$ complex were able to inhibit the growth of the C. neoformans strains. However, the inclusion of the $6 \mathrm{CN} 10$ in the HP- $\beta-\mathrm{CD}$ caused a significant improvement in the anti-Cryptococcus activity profile, promoting an increase in the activity from about 3.5 to 7 times (from 333.33-166.66 $\mu \mathrm{g} \mathrm{mL} \mathrm{mL}^{-1}$ (free drug) to $46.66 \mu \mathrm{g} \mathrm{mL} \mathrm{m}^{-1}$ (complexed drug)). This may be directly related to improved water solubility of 6CN10 upon complexation.

The results suggest that the formation of the complex between the $6 \mathrm{CN} 10$ and the 2-hydroxypropyl- $\beta$-cyclodextrin clearly improves the in vitro antifungal effect of the active compound against Cryptococcus neoformans. Furthermore, the formulation of 6CN10:HP- $\beta-C D$ complex may be a promising antifungal formulation to be used as a traditional or as a new drug delivery system.

\section{Conclusions}

In this study, a $6 \mathrm{CN} 10: \mathrm{HP}-\beta-\mathrm{CD}$ complex was successfully prepared by freeze-drying method and provides an alternative means of overcoming the low aqueous solubility of the $6 \mathrm{CN} 10$. The complexation was able to enhance the apparent solubility and thermal stability of the drug. The molecular complexation mechanism proposed by FTIR, NMR and docking data showed that the $6 \mathrm{CN} 10$ is able to form stable complexes with HP- $\beta-C D$, but preferably by the outer portion, generating the formation of both inclusion and, preferentially non-inclusion complexes. Furthermore, FTIR, Raman, TG-DTA, XRD and SEM confirm that the 6CN10:HP- $\beta-C D$ complex can lead to modifications in the physicochemical characteristics of the drug, as thermal stability and crystallinity properties. Regarding the antifungal activity, the considerable increase in 6CN10 solubility in the complexed form, potentially enhanced the in vitro antifungal efficacy of 6CN10 (up to 7-fold). The results reveal that this inclusion complex should be regarded as a promising strategy in the design of a novel formulation of $6 \mathrm{CN} 10$, and others low soluble drugs to function as new antifungal agents. Further in vivo studies comparing the $6 \mathrm{CN} 10$ and $6 \mathrm{CN} 10: \mathrm{HP}-\beta-\mathrm{CD}$ inclusion complexes will be conducted to corroborate the results of this investigation.

\section{Supplementary Information}

Supplementary data are available free of charge at http://jbcs.sbq.org.br as PDF file.

\section{Acknowledgments}

The authors are grateful to PROPESQ-UEPB for the financial support, CTPETRO-INFRA I and FINEP/ LIEM for the SEM analysis and to FACEPE/CETENE for the research grant and the XRD and FTIR/Raman analyses. 


\section{References}

1. Puterova, Z.; Krutosikova, A.; Vegh, D.; Arkivoc 2010, 209.

2. Souza, B. C. C.; De Oliveira, T. B.; Aquino, T. M.; de Lima, M. C. A.; Pitta, I. R.; Galdino, S. L.; Lima, E. O.; Goncalves-Silva, T.; Militao, G. C. G.; Scotti, L.; Scotti, M. T.; Mendonça Jr., F. J. B.; Acta Pharm. 2012, 62, 221.

3. Mendonça, F. J. B.; Lima-Neto, R. G.; de Oliveira, T. B.; de Lima, M. D. A.; Pitta, I. R.; Galdino, S. L.; da Cruz, R. M. D.; de Araujo, R. S. A.; Neves, R. P.; Lat. Am. J. Pharm. 2011, 30, 1492.

4. Scotti, L.; Scotti, M. T.; Lima, E. O.; da Silva, M. S.; de Lima, M. C. A.; Pitta, I. R.; de Moura, R. O.; de Oliveira, J. G. B.; da Cruz, R. M. D.; Mendonça Junior, F. J. B.; Molecules 2012, 17, 2298.

5. Figueiras, A.; Ribeiro, L.; Vieira, M. T.; Veiga, F.; J. Inclusion Phenom. Macrocyclic Chem. 2007, 57, 173.

6. He, Z.; Wang, Z.; Zhang, H.; Pan, X.; Su, W.; Liang, D.; Wu, C.; Acta Pharm. Sin. B 2011, 1, 254.

7. Hu, L.; Zhang, H.; Song, W.; Gu, D.; Hu, Q.; Carbohydr. Polym. 2012, 90, 1719.

8. Del Valle, E. M. M.; Process Biochem. 2004, 39, 1033.

9. Wu, H.; Liang, H.; Yuan, Q.; Wang, T.; Yan, X.; Carbohydr. Polym. 2010, 82, 613.

10. Carrier, R. L.; Miller, L. A.; Ahmed, I.; J. Control. Release 2007, 123, 78 .

11. Hwang, Y. Y.; Shin, D. C.; Nam, Y. S.; Cho, B.-K.; J. Ind. Eng. Chem. 2012, 18, 1412.

12. Lyra, M. A. M.; Soares-Sobrinho, J. L.; Figueiredo, R.; Sandes, J. M.; Lima, A. A. N.; Tenorio, R. P.; Fontes, D. A. F.; Santos, F. L. A.; Rolim, L. A.; Rolim-Neto, P. J.; J. Inclusion Phenom. Macrocyclic Chem. 2012, 73, 397.

13. Gould, S.; Scott, R. C.; Food Chem. Toxicol. 2005, 43, 1451.

14. Higuchi, T.; Connors, K. A. In Advances in Analytical Chemistry and Instrumentation, vol. 4; Reilley, C. N., ed.; 1965, p. 117.

15. Loftsson, T.; Hreinsdóttir, D.; Másson, M.; Int. J. Pharm. 2005 , $302,18$.

16. Loftsson, T.; Hreinsdottir, D.; Masson, M.; J. Inclusion Phenom. Macrocyclic Chem. 2007, 57, 545.

17. Mendonça, E. A. M.; Lira, M. C. B.; Rabello, M. M.; Cavalcanti, I. M. F.; Galdino, S. L.; Pitta, I. R.; Lima, M. C. A.; Pitta, M. G. R.; Hernandes, M. Z.; Santos-Magalhaes, N. S.; AAPS PharmSciTech 2012, 13, 1355.

18. Thomsen, R.; Christensen, M. H.; J. Med. Chem. 2006, 49, 3315.
19. Barnett, J. A.; Payne, R. W.; Yarrow, D.; Yeasts: Characteristics and Identification; Cambridge University Press: Cambridge, UK, 2000.

20. Hoog, G. S.; Guarro, J.; Gené, J.; Figueras, M. J.; Atlas of Clinical Fungi, $2^{\text {nd }}$ ed.; American Society for Microbiology: Utrecht/Reus, 2000.

21. Clinical and Laboratory Standards Institute; M27-A3 Reference Method for Broth Dilution Testing of Yeasts: Approved StandardThird Edition; CLSI: Wayne, 2008.

22. Zhou, Q.; Wei, X.; Dou, W.; Chou, G.; Wang, Z.; Carbohydr. Polym. 2013, 95, 733.

23. Loftsson, T.; Masson, M.; Brewster, M. E.; J. Pharm. Sci. 2004, 93, 1091.

24. Marques, H. M. C.; Hadgraft, J.; Kellaway, I. W.; Int. J. Pharm. 1990, 63, 259.

25. Shen, C.; Yang, X.; Wang, Y.; Zhou, J.; Chen, C.; J. Inclusion Phenom. Macrocyclic Chem. 2012, 72, 263.

26. Haiyee, Z. A.; Saim, N.; Said, M.; Illias, R. M.; Mustapha, W. A. W.; Hassan, O.; Food Chem. 2009, 114, 459.

27. Reddy, M. N.; Rehana, T.; Ramakrishna, S.; Chowdary, K. P. R.; Diwan, P. V.; AAPS PharmSci 2004, 6, 68.

28. Wang, J.; Cao, Y.; Sun, B.; Wang, C.; Food Chem. 2011, 124, 1069.

29. Tang, P.; Ma, X.; Wu, D.; Li, S.; Xu, K.; Tang, B.; Li, H.; Carbohydr. Polym. 2016, 142, 16.

30. Heise, H. M.; Kuckuk, R.; Bereck, A.; Riegel, D.; Vib. Spectrosc. 2010, 53, 19.

31. Iliescu, T.; Baia, M.; Miclaus, V.; Eur. J. Pharm. Sci. 2004, 22 , 487.

32. Li, W.; Lu, B.; Chen, F.; Yang, F.; Wang, Z.; J. Mol. Struct. 2011, 990, 244.

33. Mohan, P. R. K.; Sreelakshmi, G.; Muraleedharan, C. V.; Joseph, R.; Vib. Spectrosc. 2012, 62, 77.

34. Arrais, A.; Savarino, P.; J. Inclusion Phenom. Macrocyclic Chem. 2009, 64, 73.

35. Ceborska, M.; Zimnicka, M.; Pietrzak, M.; Troc, A.; Kozbial, M.; Lipkowski, J.; Org. Biomol. Chem. 2012, 10, 5186.

36. Pessine, F. B. T.; Calderine, A.; Alesandrino, G. L. In Magnetic Resonance Spectroscopy; Kim, D.-H., ed.; InTech: Rijeka, Croatia, 2012, ch. 12.

Submitted: February 26, 2016 Published online: May 17, 2016 